\title{
Adverse effects associated with regadenoson myocardial perfusion imaging
}

\author{
Efstathia Andrikopoulou, MD, a and Fadi G. Hage, MD, FASNC, FACC \\ a Sub-division of Non-Invasive Cardiovascular Imaging, Division of Cardiovascular Disease, \\ Department of Medicine, Brigham and Women's Hospital, Boston, MA \\ b Division of Cardiovascular Disease, Department of Medicine, University of Alabama at \\ Birmingham, Birmingham, AL \\ c Section of Cardiology, Birmingham Veterans Affairs Medical Center, Birmingham, AL
}

Received Jan 18, 2018; accepted Jan 18, 2018

doi: $10.1007 / \mathrm{s} 12350-018-1218-7$

\section{See related article, pp. 1718-1723}

\section{INTRODUCTION}

Single-photon emission computed tomography myocardial perfusion imaging (MPI) is one of the most widely used non-invasive methods for assessing patients with known or suspected coronary artery disease (CAD). ${ }^{1}$ Exercise is the preferred stressor, however, in cases of patients who either cannot exercise adequately or there are contraindications to exercise, vasodilating agents can be used instead. Of these, regadenoson is the only FDA-approved A2A adenosine receptors selective agonist; due to its selectivity and ease of use, it is the stressing agent of choice in the United States and its use is increasing in other countries. After binding to A2A receptors on smooth muscle cells, regadenoson leads to vasodilatation, predominantly of the coronary bed and secondarily of the periphery. The majority of the administered dose is renally excreted $(58 \%$ of the administered dose $)^{2}$ and its clearance is prolonged in individuals with impaired renal function. ${ }^{3}$

In addition to its ease of administration (single bolus of $200 \mathrm{mcg}$ given intravenously, IV), when

Funding Dr. Hage has received research grants from Astellas Pharma USA.

Reprint requests: Efstathia Andrikopoulou, MD, Sub-division of NonInvasive Cardiovascular Imaging, Division of Cardiovascular Disease, Department of Medicine, Brigham and Women s Hospital, 75 Francis street, ABI L1-027, Boston, MA 02115; eandrikopoulou@ bwh.harvard.edu

J Nucl Cardiol 2018;25:1724-31.

$1071-3581 / \$ 34.00$

Copyright (c) 2018 American Society of Nuclear Cardiology. compared to adenosine, regadenoson has been shown to be non-inferior for identifying perfusion defects ${ }^{4}$ and providing prognostic data. ${ }^{5-10}$ Furthermore, it is better tolerated as evidenced by a lower summed score of chest pain, dyspnea, and flushing reported by the patients ${ }^{4}$ and has a comparable safety profile. ${ }^{4}$ Despite its advantages, there still are certain undesirable effects associated with the use of regadenoson, the incidence of which is overall low. Nevertheless, it is clinically important to not only recognize these undesirable effects, but also to manage them appropriately.

In this issue of the Journal, Agrawal et al. describe two patients who underwent regadenoson MPI and experienced chest pain during the test. ${ }^{11}$ In the first patient, treatment with oral nitroglycerin worsened symptoms, led to the development of hypotension and evolution of electrocardiographic (ECG) changes with initially persistent ST-segment depression followed by ST elevation. Resting MPI and coronary angiography revealed severe multi-vessel CAD. The second patient complained of chest pain after receiving regadenoson along with evidence of ST-segment depression. Both the symptoms, as well as the ECG changes resolved following administration of IV aminophylline and the patient was able to complete his stress test. Similarly to the first case, severe multi-vessel CAD was evident on MPI and coronary angiography. The two case examples of differential response to nitroglycerin vs aminophylline serve to stress the importance of recognizing adverse effects seen with regadenoson MPI and the proper management strategies that should be used. The authors conclude that in patients with severe underlying CAD, development of chest pain and ECG changes after regadenoson most likely represents coronary steal. In such cases, nitroglycerin has the risk of causing further steal and clinical deterioration, as opposed to 
aminophylline which may offer benefit by ameliorating the extent of steal and resolving patient symptoms. ${ }^{11}$

\section{CARDIOVASCULAR ADVERSE EFFECTS}

The differential management and immediate clinical response of these two cases exemplify the importance of knowledge of the potential side effects associated with use of regadenoson and what the optimal antidote is. In the landmark ADVANCE-MPI trial, chest pain and shortness of breath were among the most frequently reported side effects of regadenoson (29\% and $28 \%$, respectively). ${ }^{4}$ Episodes of fatal and non-fatal myocardial ischemia and infarction have also been reported in association with regadenoson ${ }^{12-14}$ and as of June 2017, there were 70 cases of myocardial infarction and/or acute myocardial infarctions and 28 deaths were reported to the FDA via its adverse event reporting system (FAERS) ${ }^{15}$ There have been so far no identifiable risk factors to accurately predict and risk stratify patients for development of the above-mentioned adverse effects. ${ }^{16}$ The underlying mechanism mediating the development of chest pain and myocardial ischemia following administration of regadenoson remains unclear. It has been hypothesized that regadenosoninduced vasodilation of coronary collaterals and subsequent coronary steal may account for this (i.e., enhanced blood flow from the subendocardium to the subepicardium in a coronary territory supplied by a stenosed vessel). Another plausible explanation could be the development of hypotension and tachycardia that may accompany regadenoson. The pathogenesis of these is also not well understood, but it is believed that an exaggerated vasovagal reaction (Bezold-Jarisch reflex) in conjunction with vagal stimulation (an A2A receptormediated mechanism) in the area postrema (located at the floor of the fourth ventricle) might mediate this, ${ }^{17}$ especially in cases preceded by nausea and vomiting. ${ }^{18}$ An alternate explanation could be the A2A-mediated activation of the sympathetic afferent nerves leading to enhanced sympathetic activity and reflex vagal stimulation. ${ }^{19-21}$ This may prove particularly risky, especially in the subgroup of patients unable to tolerate hypotension, such as the elderly, those with a history of stroke, significant left ventricular outflow tract obstruction, or severe ischemic left ventricular dysfunction and in those undergoing hybrid regadenoson-exercise stress since hypotension may be exacerbated with upright posture. Finally, regadenoson itself may stimulate production of endogenous adenosine further potentiating the following effects: (a) coronary transmural steal phenomenon, (b) adenosine-related vasodilatation which may in turn result in diminished flow through collaterals and arterioles and a drop in perfusion pressure, and (c) a reduction in distal perfusion pressure due to increased flow across a stenosed vessel. These may be of particular concern in patients with known significant multi-vessel CAD with restricted coronary flow reserve.

The above adverse effects, albeit rare, deserve immediate medical attention and when observed, need to be treated appropriately, as administration of the wrong therapeutic agent may lead to further clinical deterioration. The occurrence of chest pain in a patient undergoing regadenoson MPI, with or without further evidence of myocardial ischemia, namely development of hypotension and/or ECG changes, needs to be differentiated as either being a non-specific symptom vs originating from imbalance between myocardial oxygen demand and supply and thus representing true angina. The timing of occurrence of the pain is of critical importance, as evidenced by the two case reports by Agarwal et al. ${ }^{11}$ Myocardial ischemia that develops in close proximity to regadenoson administration will respond better to aminophylline as opposed to nitroglycerin. The latter may in fact potentiate regadenosoninduced steal, coronary vasodilation, and reduced perfusion pressure of the coronary bed, the cumulative effect of which may result in worsening myocardial ischemia, or even development of infarction, and rapid deterioration of the patient. This is in contrast to myocardial ischemia occurring independently of regadenoson administration (or after a significant delay from its administration) which may benefit from nitroglycerin. Although the duration of coronary dilation in response to regadenoson may be prolonged, significant hyperemia ( $>$ twofold increase over baseline) usually lasts less than 10 minutes. ${ }^{19}$ Therefore, it is likely that coronary steal would occur during this window although this has not been systematically evaluated to our knowledge.

The two most common cardiovascular side effects following administration of regadenoson include modest reductions in systolic and diastolic blood pressure (average of 13 and $8 \mathrm{mmHg}$, respectively) and modest increase in heart rate (average increase of $25 \pm 11 \mathrm{bpm}$ ) as documented in the ADVANCE-MPI trials. ${ }^{4}$ Based on animal experiments, it is now clear that regadenosonmediated tachycardia results from either direct sympathetic stimulation or withdrawal of vagal tone ${ }^{17,20,21}$ and is not a baroreflex-mediated epiphenomenon secondary to peripheral vasodilation as once thought. The heart rate response (HRR) to regadenoson is a prognostically important, non-perfusion-derived MPI index ${ }^{22}$ and can be calculated as the percent difference in heart rate from baseline with lower values reflecting worse prognosis. Values greater than $30 \%$ are thought normal, whereas less than $15 \%$ abnormal or blunted. ${ }^{23}$ Older age, male gender, reduced left ventricular systolic function, 
perfusion defects, and history of obesity, diabetes mellitus, and chronic kidney disease have all been shown to correlate with a decreased HRR to regadenoson. ${ }^{22-28}$

Given its selectivity for the A2A receptors, A1 receptor-mediated cardiac undesirable effects, namely sinoatrial nodal dysfunction and atrioventricular (AV) block occur less frequently with regadenoson compared to adenosine. This was confirmed in the ADVANCEMPI trials, where $2.8 \%$ of patients developed firstdegree AV block and only one patient had Wenckebach second-degree AV block and there were no instances of complete heart block or asystole. ${ }^{4}$ Despite this initial observation, there have since been isolated case reports and small case series describing the occurrence of de novo advanced heart block and asystole following regadenoson and requiring immediate management and stabilization. ${ }^{29-35}$ As of June 2017, a total of 56 cases of third-degree heart block and 26 cases of sinus arrest associated with regadenoson stress testing were reported via FAERS. ${ }^{15}$ In a recent meta-analysis, the incidence of overall and high-grade AV block-defined as secondand third-degree AV block-related to the administration of regadenoson at the dose given during MPI was low (less than $0.5 \%$ ) and observed much less frequently with regadenoson compared to adenosine (incidence of de novo overall AV block with adenosine was 8.58\%; 95\% CI $5.55 \%$ to $12.21 \%$ vs. regadenoson which was $0.30 \%$; $95 \%$ CI $0.04 \%$ to $0.82 \%, P<0.001$, OR 30.6 ; 95\% CI 11.0 to 85.3; incidence of high-grade AV block for adenosine was $5.21 \%$; $95 \%$ CI $2.81 \%-8.30 \%$ vs regadenoson which was $0.05 \%$; $95 \% \mathrm{CI}<0.001 \%$ $0.19 \%, P<0.001$, OR $77.2 ; 95 \%$ CI 20.3 to 293.0 ) (Figure 1). ${ }^{36}$ It remains unclear why certain patients develop sinoatrial and AV node dysfunction following use of regadenoson. Similarly to the development of chest pain and myocardial ischemia, conduction disturbances in response to regadenoson, have also been postulated to result from neural-mediated pathways, namely (a) a prominent vasovagal reaction and (b) pronounced sympathetic activity and reflex vagal stimulation. Another mechanism, also overlapping with the pathogenesis of myocardial ischemia is the regadenoson-mediated increased production of endogenous adenosine. This may be more evident in the subgroup of patients with severe underlying CAD or extensive collateral circulation. In this subset of patients, regadenoson may lead to coronary steal or a sudden drop in systemic blood pressure, followed by ischemia, which may in turn lead to overproduction of adenosine and activation of the $\mathrm{A} 1$ receptors in the sinoatrial and $\mathrm{AV}$ nodes and suppressed conduction. Current ASNC guidelines caution against using regadenoson in patients with known sinoatrial and/or second- or third-degree AV block without a functioning pacemaker. Profound sinus bradycardia and Mobitz type 1 second-degree AV block (Wenckebach block) are listed as relative contraindications.

Other less frequent cardiovascular side effects following regadenoson include ventricular and supraventricular tachycardias, such as atrial fibrillation and flutter. ${ }^{37}$ Prolongation of the QT interval might also occur as a result of regadenoson-induced tachycardia and shortening of the R-R interval without appropriate shortening of the QT interval. ${ }^{20,38}$ This type of QT prolongation has not been associated with torsades de pointes or sudden cardiac death. Table 1 lists the cardiovascular side effects that may follow use of regadenoson and their respective treatment.

\section{NON-CARDIOVASCULAR ADVERSE EFFECTS}

Given its high selectivity for the A2A receptors, regadenoson was initially anticipated to have been free of pulmonary-related side effects due to $\mathrm{A} 2 \mathrm{~B}$ and $\mathrm{A} 3$ receptor activation. Initial large-scale trials using regadenoson either excluded patients with known bronchospastic/bronchorestrictive lung disease or only allowed for inclusion of a small fraction of patients with known COPD or asthma (range 6\%-16\%). ${ }^{4,35,39,40}$ Following initial post-marketing reports of wheezing, dyspnea, and respiratory arrest, ${ }^{16}$ the use of regadenoson in patients with COPD and/or asthma was examined in randomized, double-blinded, cross-over, placebo-controlled trials that included patients with moderate-severe COPD (RegCOPD) and mild-moderate asthma (RegAsthma). ${ }^{41,42}$ These showed that use of regadenoson in the above patient subgroups was well tolerated without significant changes in respiratory rate, FVC, FEV1, new-onset wheezing, or bronchoconstriction and oxygen saturation compared to placebo. ${ }^{41,42}$ Of note, dyspnea was reported in $61 \%$ of patients in the regadenoson group vs $0 \%$ in the placebo group, this however, was not confirmed by objective measurements. None of the patients in these studies required treatment with bronchodilators or oxygen. ${ }^{41,42}$ The above findings have been confirmed by larger studies showing a safe and favorable pulmonary profile of regadenoson. ${ }^{43}$ Adding low level exercise to regadenoson has been proposed as one way to attempt to decrease the development of pulmonary side effects and improve tolerability in patients with COPD and/or asthma. ${ }^{35,44}$ Data are still limited and definitive conclusions cannot be drawn. ${ }^{45}$ The most critical component of combination stress testing is careful selection of the patients that may benefit. ${ }^{45}$ The ones included in the studies had relatively stable COPD/asthma, their asthma severity being at the most moderate, without recent exacerbations and only 


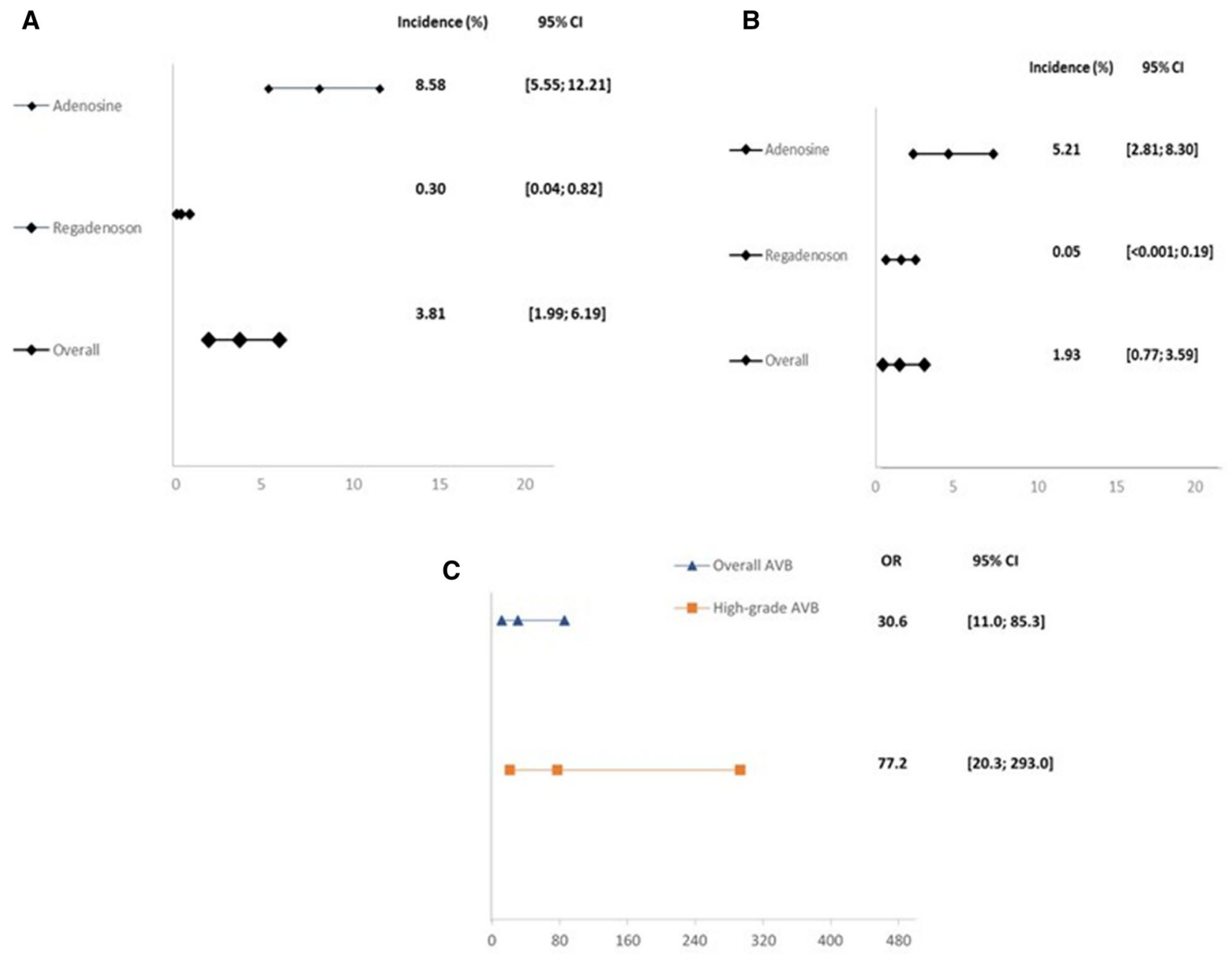

Figure 1. A Incidence of overall AVB following administration of adenosine vs regadenoson, as reported in the literature. B Incidence of high-grade AVB following administration of adenosine vs. regadenoson, as reported in the literature. $\mathbf{C}$ Odds ratio for overall and high-grade AVB associated with administration of adenosine and regadenoson stress SPECT-MPI. Forest plots for $\mathbf{A}$ and $\mathbf{B}$ and data for odds ratio obtained and modified from the meta-analysis by Andrikopoulou et al. ${ }^{36}$ Highgrade AVB defined as any occurrence of second- and/or third-degree AVB. $A V B$, atrioventricular block; SPECT-MPI, single-photon emission computed tomography myocardial perfusion imaging.

seldom used their rescue inhalers. More randomized trials are needed to accurately define the safety of regadenoson in patients with pulmonary disease. ${ }^{45}$ Regadenoson should be avoided in patients with severe COPD or asthma with active bronchoconstriction (i.e., actively wheezing in the stress laboratory). In these cases, alternative stressors and/or modalities should be used, such as dobutamine MPI, or stress echocardiography. In patients with known severe pulmonary disease but who are not having active wheezing consideration should be given to administering supplemental oxygen through a mask or nasal cannula and having nebulizers and inhalers at hand, in case they are needed, or prophylactically giving bronchodilators prior to regadenoson.
Gastrointestinal side effects, namely nausea, diarrhea, and abdominal discomfort have been reported in about $2 \%-8 \%$ of patients following regadenoson. ${ }^{4,35,39,40}$ These adverse effects occur more frequently in patients with advanced renal disease. ${ }^{39,40}$ With the exception of diarrhea, these are short-lived, and can be easily managed conservatively.

One of the most dreadful complications associated with the use of regadenoson, albeit rare, is new-onset or recurrent convulsive seizures. ${ }^{16,37,46,47}$ As of 2017, a total of 55 cases of convulsions and 11 cases of seizurelike and partial seizures were reported to the FDA, ${ }^{15}$ though the exact de novo occurrence of seizures with regadenoson MPI is unknown. The pathogenetic mechanism is not yet delineated; It is thought that activation 


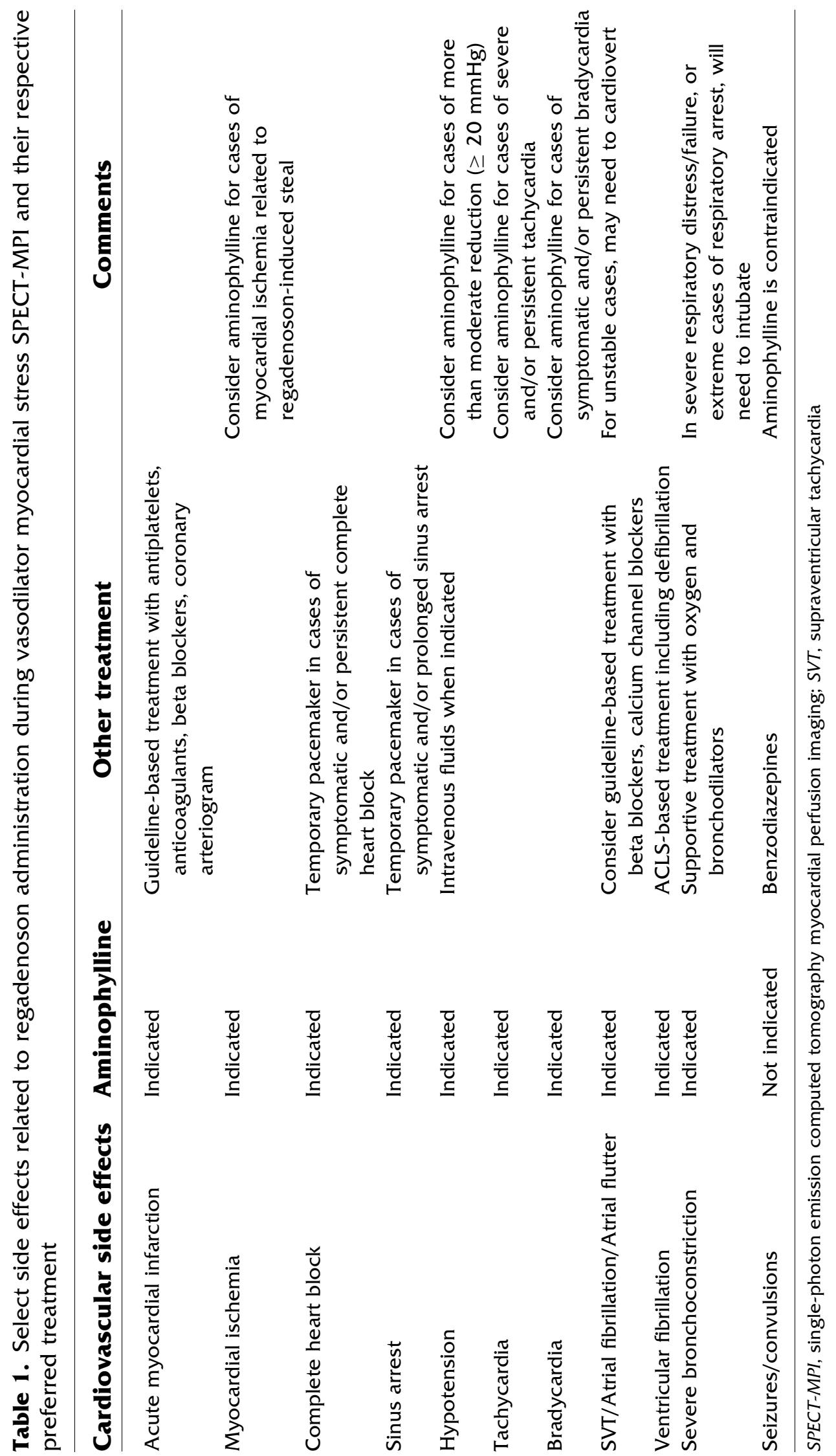




\section{Events in Reports That Contain REGADENOSON}

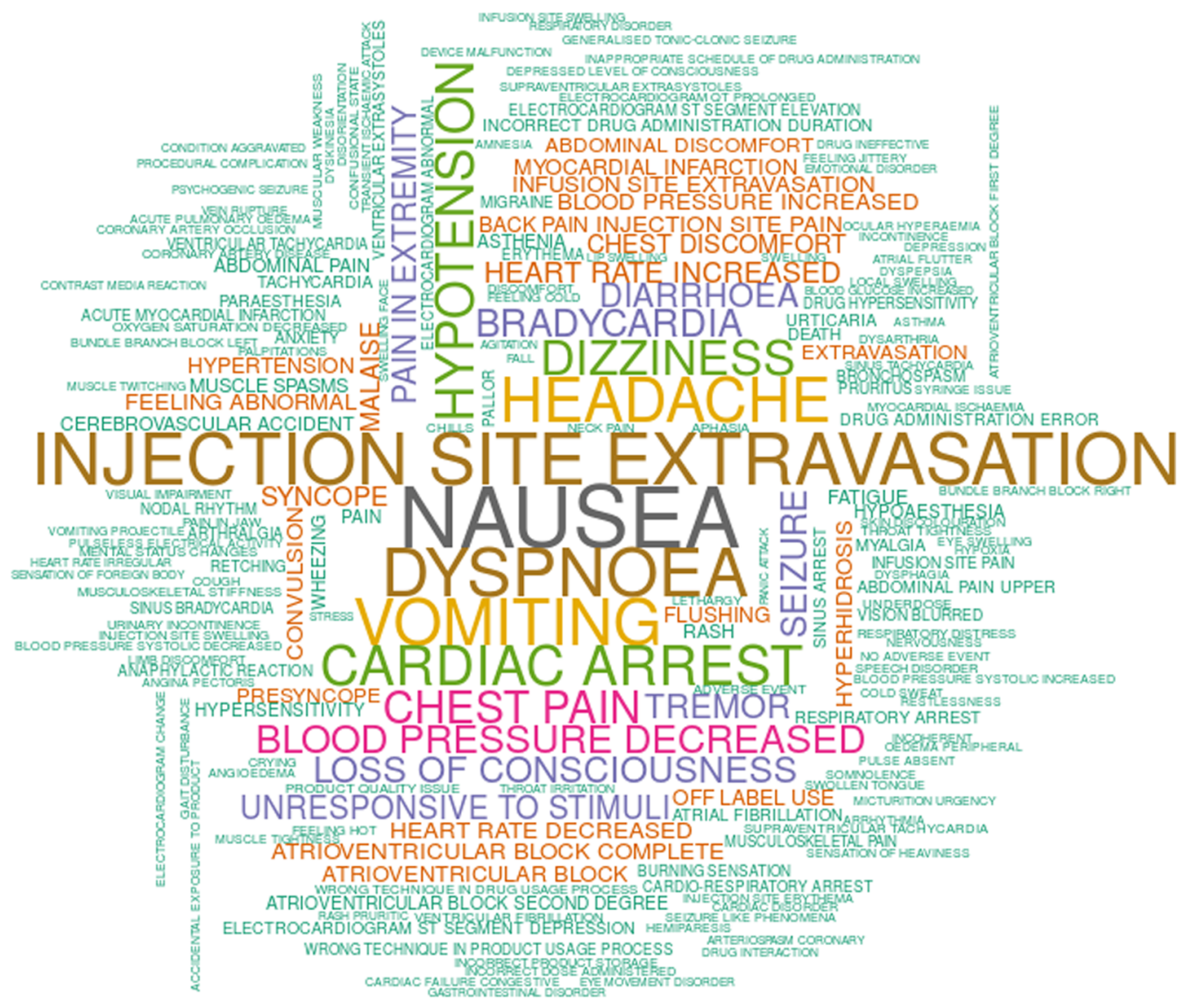

Figure 2. Side effects following administration of regadenoson that have been reported to the FDA/ FAERS. Size of the word corresponds to the frequency of reports submitted to the FDA. Figure adopted from and available at the official FAERS website. https://openfda.shinyapps.io/dash/ (accessed on 1/11/2018).

of the $\mathrm{A} 2 \mathrm{~A}$ receptors in the central nervous system, primarily at the nucleus accumbens, striatum, and tuberculum olfactorium, and to a lesser extent the cortex and hippocampus, results in inhibition of the A1 neuroprotective effects and instead activates glutamatergic excitatory pathways, ultimately leading to potentiation of cortical and limbic seizures. ${ }^{48-51}$ The development of seizures was described in a small case series of three patients receiving regadenoson. ${ }^{46}$ In two of them, those were episodes of recurrent seizures (both patients were chronically treated with anticonvulsive medications and they had been stable for years). In the third patient, these were new-onset seizures. ${ }^{46}$ In all three patients, seizures were noted within 2-5 minutes of regadenoson administration and in all three, episodes began as secondary and quickly converted to secondary generalized with verbal unresponsiveness. ${ }^{46}$ Aminophylline is not a good option for treating regadenosoninduced seizures not only because it is not effective in this setting but also since it may even perpetuate the seizures. ${ }^{46}$ Benzodiazepines are the treatment of choice. Further treatment may include other anticonvulsive therapies. Risk stratifying patients for the development of seizures following regadenoson is not yet feasible, though a known history of seizures is definitely a risk factor. Special attention should be given when obtaining the patients' medical history with respect to prior seizures. High level of caution is recommended even if the patient has been relatively free of seizures and consideration of alternate stressors and/or modalities is warranted in patients who have been having active seizures. Benzodiazepines must be at hand. Current ASNC guidelines list seizure disorder as a relative contraindication for regadenoson administration. ${ }^{37}$

Non-specific side effects, such as myalgias, tremors, and hypersensitivity reactions have all been reported following regadenoson, but they are all short-lived and usually self-terminate. ${ }^{37} \mathrm{An}$ up-to-date list of all adverse 
effects reported following injection with regadenoson in patients undergoing vasodilator stress testing can be found in the website of FDA ${ }^{15}$ (Figure 2). The most serious side effects associated with the administration of regadenoson for MPI along with their recommended management are listed in Table 1.

\section{CONCLUSION}

As the population ages, use of vasodilators with MPI instead of exercise will continue to rise. A2A selective agonists, such as regadenoson, are easier to use and associated with better safety and tolerability profiles than non-selective agents such as adenosine and dipyridamole. Despite its advantage and its diagnostic and prognostic value, clinicians should be aware of the side effects associated with regadenoson. The vast majority of these side effects are short-lived, benign, and spontaneously terminate. On rare occasions, however, more serious cardiovascular and neurological adverse events may develop, namely symptomatic myocardial ischemia, infarction, high-grade AV block, asystole, and seizures. Such events can be avoided with careful risk stratification and selection of patients prior to administering regadenoson and personalizing the potential risks and benefits for each patient individually. Clinicians should be aware of the preferred method of managing possible side effects and know when aminophylline is safe to be administered.

\section{Disclosure}

Dr. Hage reports investigator-initiated grant support from Astellas Pharma. Efstathia Andrikopoulou has no disclosure.

\section{References}

1. Wolk MJ, Bailey SR, Doherty JU, Douglas PS, Hendel RC, Kramer CM, et al ACCF/AHA/ASE/ASNC/HFSA/HRS/SCAI/ SCCT/SCMR/STS 2013 multimodality appropriate use criteria for the detection and risk assessment of stable ischemic heart disease: a report of the American College of Cardiology Foundation Appropriate Use Criteria Task Force, American Heart Association, American Society of Echocardiography, American Society of Nuclear Cardiology, Heart Failure Society of America, Heart Rhythm Society, Society for Cardiovascular Angiography and Interventions, Society of Cardiovascular Computed Tomography, Society for Cardiovascular Magnetic Resonance, and Society of Thoracic Surgeons. J Am Coll Cardiol 2014;63(4):380-406.

2. Gordi T, Frohna P, Sun HL, Wolff A, Belardinelli L, Lieu H. A population pharmacokinetic/pharmacodynamic analysis of regadenoson, an adenosine A2A-receptor agonist, in healthy male volunteers. Clin Pharmacokinet 2006;45:1201-12.
3. Gordi T, Blackburn B, Lieu H. Regadenoson pharmacokinetics and tolerability in subjects with impaired renal function. J Clin Pharmacol 2007:47:825-33.

4. Iskandrian AE, Bateman TM, Belardinelli L, Blackburn B, Cerqueira MD, Hendel RC, et al Adenosine versus regadenoson comparative evaluation in myocardial perfusion imaging: results of the ADVANCE phase 3 multicenter international trial. J Nucl Cardiol 2007;14:645-58.

5. Iqbal FM, Hage FG, Ahmed A, Dean PJ, Raslan S, Heo J, et al Comparison of the prognostic value of normal regadenoson with normal adenosine myocardial perfusion imaging with propensity score matching. JACC Cardiovasc Imaging 2012;5(10):1014-21.

6. Bhatti S, Hakeem A, Dhanalakota S, Palani G, Husain Z, Jacobsen G, et al Prognostic value of regadenoson myocardial single-photon emission computed tomography in patients with different degrees of renal dysfunction. Eur Heart $\mathbf{J}$ Cardiovasc Imaging 2014;15(8):933-40.

7. Hage FG, Ghimire G, Lester D, Mckay J, Bleich S, El-Hajj S, et al The prognostic value of regadenoson myocardial perfusion imaging. J Nucl Cardiol 2015;22(6):1214-21.

8. Farzaneh-Far A, Shaw LK, Dunning A, Oldan JD, O'Connor CM, Borges-Neto S. Comparison of the prognostic value of regadenoson and adenosine myocardial perfusion imaging. J Nucl Cardiol 2015;22(4):600-7.

9. El-Hajj S, AlJaroudi WA, Farag A, Bleich S, Manaoragada P, Iskandrian $\mathrm{AE}$, et al Effect of changes in perfusion defect size during serial regadenoson myocardial perfusion imaging on cardiovascular outcomes in high-risk patients. J Nucl Cardiol 2016;23(1):101-12.

10. Doukky R, Fughhi I, Campagnoli T, Wassouf M, Ali A. The prognostic value of regadenoson SPECT myocardial perfusion imaging in patients with end-stage renal disease. J Nucl Cardiol 2017;24(1):112-8.

11. Agrawal V, Hosey C, Smith G, Shah C. Detrimental effects of nitroglycerin use during regadenoson vasodilator stress testing: a cautionary tale. J Nucl Cardiol 2018.

12. Hsi DH, Marreddy R, Moshiyakhov M, Luft U. Regadenoson induced acute ST segment elevation myocardial infarction and multivessel coronary thrombosis. J Nucl Cardiol 2013;20:481-4.

13. Shah S, Parra D, Rosenstein RS. Acute myocardial infarction during regadenoson myocardial perfusion imaging. Pharmacotherapy 2013;33:905.

14. Lexiscan ${ }^{\circledR}$ (regadenoson) injection for intravenous use [package insert]. Northbrook, IL: Astellas Pharma US; 2013.

15. https://openfda.shinyapps.io/dash/.

16. Hage FG. Regadenoson for myocardial perfusion imaging: Is it safe? J Nucl Cardiol 2014;21(5):871-6 Erratum in: J Nucl Cardiol. 2014 Dec;21(6):1266.

17. Kang MJ, Park MS, Shin IC, Koh HC. Modification of cardiovascular response of posterior hypothalamic adenosine $\mathrm{A}(2)$ receptor stimulation by adenylate cylase, guanylate cyclase and by K(ATP) channel blockade in anesthetized rats. Neurosci Lett 2003;344:57-61.

18. Palmer ED. The abnormal upper gastrointestinal vasovagal reflexes that affect the heart. Am J Gastroenterol 1976;66(51322): 29 .

19. Lieu HD, Shryock JC, von Mering GO, Gordi T, Blackburn B, Olmsted AW, et al Regadenoson, a selective A2A adenosine receptor agonist, causes dose-dependent increases in coronary blood flow velocity in humans. J Nucl Cardiol 2007;14:514-20.

20. Zhao G, Serpllion S, Shryock J, Messina E, Xu X, Ochoa M, et al Regadenoson, a novel pharmacologic stress agent for use in myocardial perfusion imaging, does not have a direct effect on the 
QT interval in conscious dogs. J Cardiovasc Pharmacol 2008;52:467-73.

21. Dhalla AK, Wong M, Wang W, Biaggioni I, Belardinelli L. Tachycardia caused by A $2 \mathrm{~A}$ adenosine receptor agonists is mediated by direct sympathoexcitation in awake rats. $\mathrm{J}$ Pharmacol Exp Ther 2006;316:695-702.

22. Hage FG, Dean P, Iqbal F, Heo J, Iskandrian AE. A blunted heart rate response to regadenoson is an independent prognostic indicator in patients undergoing myocardial perfusion imaging. J Nucl Cardiol 2011;18:1086-94.

23. Andrikopoulou E, Hage FG. Heart rate response to regadenoson: making the case for its value in clinical practice. J Nucl Cardiol 2016;23(3):575-580.

24. Hage FG, Perry G, Heo J, Iskandrian AE. Blunting of the heart rate response to adenosine and regadenoson in relation to hyperglycemia and the metabolic syndrome. Am J Cardiol 2010;105(6):839-43.

25. Hage FG, Dean P, Bhatia V, Iqbal F, Heo J, Iskandrian AE. The prognostic value of the heart rate response to adenosine in relation to diabetes mellitus and chronic kidney disease. Am Heart $\mathbf{J}$ 2011;162:356-62.

26. Hage FG, Wackers FJ, Bansal S, Chyun DA, Young LH, Inzucchi SE, et al. The heart rate response to adenosine: a simple predictor of adverse cardiac outcomes in asymptomatic patients with type 2 diabetes. Int J Cardiol 2013;167:2952-7.

27. AlJaroudi W, Campagnoli T, Fughhi I, Wassouf M, Ali A, Doukky R. Prognostic value of heart rate response during regadenoson stress myocardial perfusion imaging in patients with end stage renal disease. J Nucl Cardiol 2015;23(3):560-9.

28. Andrikopoulou E, AlJaroudi WA, Farag A, Lester D, Patel H, Iskandrian $\mathrm{AE}$, et al. The reproducibility and prognostic value of serial measurements of heart rate response to regadenoson during myocardial perfusion imaging. Eur J Nucl Med Mol Imaging 2016;43(8):1493-502.

29. Pandit A, Unzek-Freiman S. Complete heart block associated with regadenoson: a real side effect. J Nucl Cardiol 2012;19:1236-9.

30. Grady EC, Barron JT, Wagner RH. Development of asystole requiring cardiac resuscitation after the administration of regadenoson in a patient with pulmonary fibrosis receiving nacetylcysteine. J Nucl Cardiol 2011;18:521-5.

31. Underwood SR, Latus KA, Reyes E, Standbridge K, Walker S, Wechalekar K. Regadenoson-induced bradycardia and hypotension: possible mechanism and antidote. J Nucl Cardiol 2014;21(5): 1040.

32. Brinkert M, Reyes E, Walker S, Latus K, Maenhout A, Mizumoto $\mathrm{R}$, et al Regadenoson in Europe: first-year experience of regadenoson stress combined with submaximal exercise in patients undergoing myocardial perfusion scintigraphy. Eur J Nucl Med Mol Imaging 2014;41:511-21.

33. Agarwal V, DePuey EG. Advanced heart block and unresponsiveness after regadenoson administration during myocardial SPECT study. Int J Cardiol 2014;176:e49-e51.

34. Rosenblatt J, Mooney D, Dunn T, Cohen M. Asystole following regadenoson infusion in stable outpatients. J Nucl Cardiol 2014;21:862-8.

35. Kwon DH, Cerqueira MD, Young R, et al Lessons from regadenoson and low-level treadmill/regadenoson myocardial perfusion imaging: initial clinical experience in 1263 patients. J Nucl Cardiol 2010;17(5):853-7.

36. Andrikopoulou E, Morgan CJ, Brice L, Bajaj NS, Doppalapudi H, Iskandrian $\mathrm{AE}$, et al Incidence of atrioventricular block with vasodilator stress SPECT: a meta-analysis. J Nucl Cardiol. 2017 https://doi.org/10.1007/s12350-017-1081-y.

37. Henzlova MJ, Duvall WL, Einstein AJ, Travin MI, Verberne HJ. ASNC imaging guidelines for SPECT nuclear cardiology procedures: Stress, protocols, and tracers. J Nucl Cardiol 2016;23(3):606-39.

38. Rafiq A, Chughtai T, Ashraf U, et al Regadenoson administration during pharmacological stress test causes prolonged QT interval. Abstract 19616. Circulation 2015;132(Supp 3):A19616.

39. Doukky R, Morales Demori R, Jain S, Kiriakos R, Mwansa V, Calvin JE. Attenuation of the side effect profile of regadenoson: a randomized double-blinded placebo-controlled study with aminophylline in patients undergoing myocardial perfusion imaging. "The ASSUAGE trial". J Nucl Cardiol 2012;19:448-57.

40. Doukky R, Rangel MO, Dick R, Wassouf M, Alqaid A, Margeta B. Attenuation of the side effect profile of regadenoson: a randomized double-blind placebo-controlled study with aminophylline in patients undergoing myocardial perfusion imaging and have severe chronic kidney disease-The ASSUAGE-CKD trial. Int J Cardiovasc Imaging 2013;29:1029-37.

41. Thomas GS, Tammelin BR, Schiffman GL, et al Safety of regadenoson, a selective adenosine A2A agonist, in patients with chronic obstructive pulmonary disease: a randomized, doubleblind, placebo-controlled trial (RegCOPD trial). J Nucl Cardiol 2008;15(3):319-28.

42. Leaker BR, O'Connor B, Hansel TT, et al Safety of regadenoson, an adenosine A2A receptor agonist for myocardial perfusion imaging, in mild asthma and moderate asthma patients: a randomized, double-blind, placebo-controlled trial. J Nucl Cardiol 2008;15(3):329-36.

43. Husain Z, Palani G, Cabrera R, et al Hemodynamic response, arrhythmic risk, and overall safety of regadenoson as a pharmacologic stress agent for myocardial perfusion imaging in chronic obstructive pulmonary disease and bronchial asthma patients. Int J Cardiovasc Imaging 2012;28(7):1841-9.

44. Henzlova MJ, Cerqueira MD, Mahmarian JJ. Yao SS; Quality Assurance Committee of the American Society of Nuclear Cardiology. Stress protocols and tracers. J Nucl Cardiol 2006;13(6):e80-e90.

45. Golzar Y, Doukky R. Regadenoson use in patients with chronic obstructive pulmonary disease: the state of current knowledge. Int J Chron Obstruct Pulmon Dis 2014;22(9):129-37.

46. Page RL 2nd, Spurck P, Bainbridge JL, Michalek J, Quaife RA. Seizures associated with regadenoson: a case series. J Nucl Cardiol 2012;19:389-91.

47. Agarwal V, DePuey EG. Regadenoson and seizures: a real clinical concern. J Nucl Cardiol 2014;21(5):869-70.

48. Fredholm BB. Adenosine receptors as targets for drug development. Drug News Perspect 2003;16:283-9.

49. Grant GA, Meno JR, Nguyen TS, Stanness KA, Janigro D, Winn RH. Adenosine-induced modulation of excitatory amino acid transport across isolated brain arterioles. J Neurosurg 2003;98:554-60.

50. Boison D. Adenosine and epilepsy: from therapeutic rationale to new therapeutic strategies. Neuroscientist 2005;11:25-36.

51. Fukuda M, Suzuki Y, Hino H, Morimoto T, Ishii E. Activation of central adenosine $\mathrm{A}(2 \mathrm{~A})$ receptors lowers the seizure threshold of hyperthermia-induced seizure in childhood rats. Seizure 2011;20:156-9. 